\title{
Assessment of the efficiency of social innovative-and-investment projects according to the social sphere direction
}

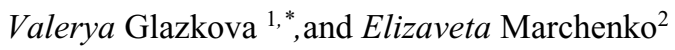 \\ ${ }^{1}$ Moscow State University of Civil Engineering, Yaroslavskoe shosse, 26, Moscow, 129337, Russia \\ 2 Vladimir State University, named after Alexander and Nikolay Stoletovs, 600014, Belokonskiy \\ street 2/7, Vladimir, Russia
}

\begin{abstract}
The review of innovative activity in the Moscow region, the main tendencies of the region's development (including the social sphere) and also the analysis of the existing legislation of the region in the field of assessment of efficiency of social projects is carried out in the article. The article is devoted to the problem of assessment of efficiency of social innovative-and-investment projects. Social innovations are considered as one of the main instruments of the increase in the level and quality of the population life and also as the factor of sustainable urban development as whole. The assumption is made, that to the forefront of the assessment of the efficiency of social innovative-and-investment projects there has to be a calculation not of efficiency, but off effectiveness of the project, and also the idea, that indicators of effectiveness need to be grouped according to the social directions (housing-and-communal services, education, municipal healthcare, culture, sport and physical culture, transport).
\end{abstract}

\section{Introduction}

Innovations become one of the main driving forces in development of national economy and an important element of the development of all spheres of the social activity, they influence on the structure of social production.

G. Tard investigated in the works the value of inventions for the social progress, the relation of society to inventions and innovations. N.D. Kondratyev in his theory of "big cycles" noted, that inventions and innovations exert powerful impact on all the course of economic dynamics and on the social progress in particular [1]. Similarly, in works by E.M. Rogers, J. Zaltmen, T. Parsons and others, innovations are considered as the mechanism of the general process of social changes [2].

P. Rozanvallon and B. Santo suggested to consider the most important problems of the present time through the prism of "sociality", assigning a significant role to social innovations [3]. P. Druker and M. Young considered social innovations to be the fundamental moment of social business [4]. The similar thought was also put forward by J.

\footnotetext{
1. ${ }^{*}$ Corresponding author: leram86@mail.ru
} 
Schumpeter: according to J. Schumpeter, innovations create the development basis, and act as its generator [5].

It is necessary to agree that social-and-economic development of Russia to a large extent is defined today by social innovations which can serve as the main instrument of improvement of quality of life of the population.

\section{State-of-the-Art}

Considering innovative activity of the Moscow region, is leading in Central Federal District according to the volume of innovative production, it should be noted that today innovative projects in various spheres (industry, construction, transport, etc.) are considered and implemented in the territory of the region. In 2015 the organizations of the Moscow region produced innovative goods, works and services (innovative production) for the amount over 294 billion rubles. According to the total amount of innovative production the Moscow region takes the third place in the Russian Federation.

The share of innovative production in the total amount of the shipped production in 2015 made 13.7\%: in comparison with 2010 this indicator grew by 1.7 times (in 2010 the share of innovative production in the total amount of shipped production made $8.1 \%$ ).

Costs of technological innovations of the organizations in 2015 made more than 134 billion rubles. The strategy of social-and-economic development of the Moscow region till 2020 provides increase in the share of internal costs of research and development in a gross regional product from $3.5 \%$ in 2005 to $8 \%$ in 2020 , the number of innovatively active organizations with 138 to 500 (in 2015433 organizations were engaged in innovative activity).

In 2016 the organizations of the Moscow region have developed 109 advanced production technologies (that makes $20 \%$ of all advanced technologies in Central Federal District and 7.1\% of advanced technologies in Russia). 16532 units of advanced production technologies are used in the region (that makes $22.8 \%$ of all the used advanced technologies of Central Federal District and 7.1\% of all the used advanced technologies of Russia).

Among the most ambitious innovative projects, realized in the territory of the Moscow region, experts name the construction of the central ring highway, allowing to connect everything the region of the Moscow region, construction of the line of easily rail transport, creation of electro-charging infrastructure (stations of charging for electric vehicles), construction of a collider of NICA in Dubna, creation of energy saving houses [6], etc.

We will notice that full innovative process represents the set of procedures and means by means of which discovery or the idea turn not only into a technological innovation, but also into a social innovation, including, innovations in education, medicine, culture, housing and communal services and other social spheres [7].

Main objective of innovative activity in the social sphere is the solution of social problems of modern society. If the offered innovation allows to reduce at least sharpness of the social problem, support of such innovations has to be provided $[8,9]$.

As innovative projects in the social sphere, as well as in any other sphere, cannot be implemented without investment investments, it is necessary to consider the social innovative-and-investment project (SIIP).

The social innovative-and-investment project is studied as a complex of measures and actions (works, services, acquisitions, managerial operations and decisions) directed to the improvement of quality of life and satisfaction of social needs of the interested participants as a result of implementation of the technical, organizational and marketing innovations to the social sphere and demanding for the realization of implementation of investments [10].

SIIP has all the features of the innovative project: innovative-and-scientific as well as intellectual potential is used during its implementation for the purpose of receiving the new 
product (service), satisfying the consumer demand in competitive goods and services. Such a project is directed to the achievement of specific goals and tasks on the priority directions of development, has a high risk and existence of options of modification at all stages of its life cycle.

Speaking about any social innovations in Moscow region, it should be noted that goods for the sum of 373.48 billion rubles, including $39.3 \%$ of innovative goods, works, services were made in 2015 by the organizations of a services sector of the Moscow region. Dynamics of these indicators is presented in the figure 1.

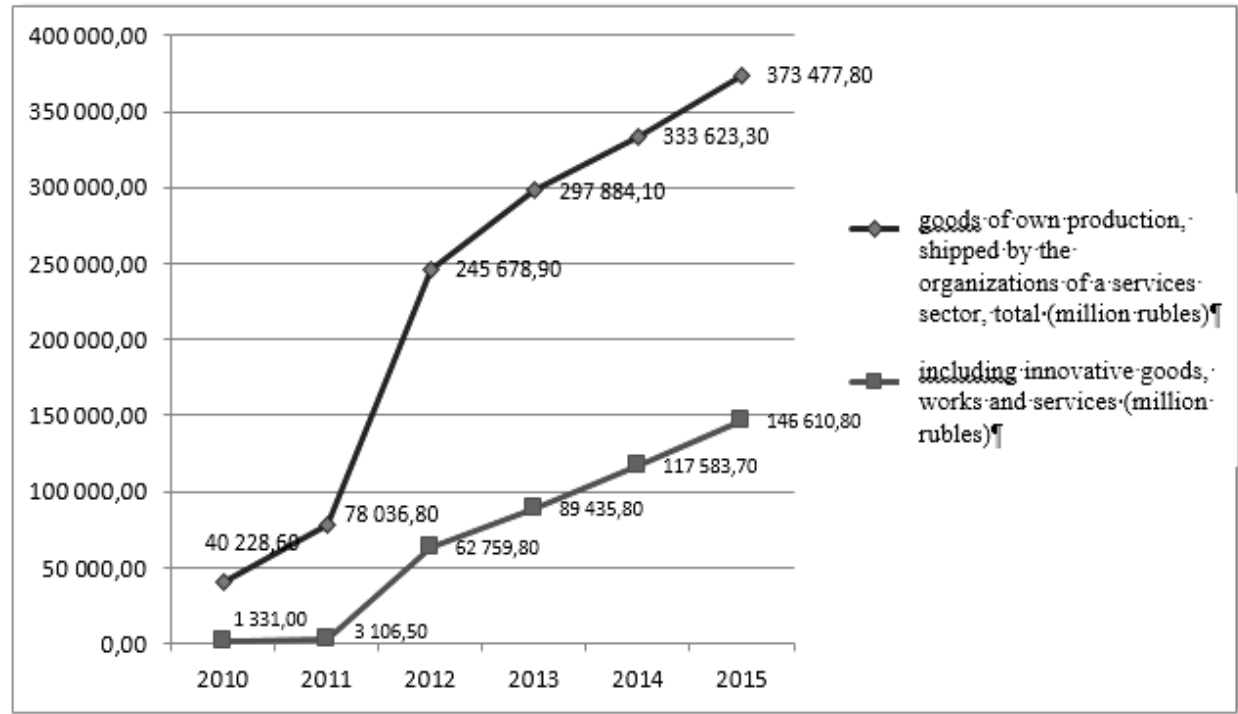

Fig. 1. Dynamics of goods, works, services (including innovative), shipped by the organizations of a services sector of the Moscow region in 2010 - 2015.

The share of innovative goods in the total amount of the made goods in a services sector since 2010 (3.31\%) has increased by 11.86 times by 2015 (39.26\%). At the same time, the quantity of goods, made in a services sector for this period has increased by 9.28 times (from 40.2 billion rubles in 2010 to 373.5 billion rubles in 2015), and the quantity of innovative goods, services has increased by 110.15 times (from 1.3 billion rubles in 2010 to 146.1 billion rubles in 2015).

\section{Results}

In spite of all the positive tendencies of innovative development of the Moscow region, we will note that the region holds only the 28th place on quality of innovative policy [10]. Such situation is caused by the absence in the region of uniform council for scientific and technical development, the approved state programs on development of innovations, the insufficient number of regional laws on scientific and technical and innovative activity.

The mechanism of assessment of the efficiency of social innovative-and-investment projects, fixed legislatively could become an important step in this direction. The regional legislation of the Moscow region in this question is limited to the provision on assessment of efficiency of social investment projects on the basis of integrated assessment by mark accounting of qualitative and quantitative criteria. Qualitative parameters in the technique of the Moscow region are estimated according a scale from 0 to 1 points. Assessment of some quantitative indices is made on the basis of weight coefficients on a scale from 0 to 
100. Division of values of weight coefficients of quantitative criteria to destination of a construction object is of the interest of a technique of the Moscow region:

- healthcare, education, culture and sport, municipal infrastructure, office buildings, environmental protection;

- subjects to production appointment, transport infrastructure, infrastructure of national innovative system, etc.

Depending on branch purpose of the facility also the corresponding set of indicators is presented that allows to carry out more detailed assessment of efficiency of the social investment project. But a lack of this mechanism of assessment is the limited list of the quantitative indices presented in a technique.

The technique of assessment of social projects [10] developed by authors is based on an effectiveness priority over efficiency and also on the principle of selective (selective) management of SIIP. For this purpose indicators of social efficiency of the innovative-andinvestment project have been developed for 6 directions of the social sphere. The system of indicators for projects in education and housing-and-communal services is presented in table 1 .

Calculation of social efficiency of SIIP according to the indicators, presented in the Table 1 is performed by summation of the work of the indicator, considering the increase in the $i_{\text {th }}$ indicator in the considered direction (it is assessed in points on the basis of results of expert assessment) and weight coefficient for the corresponding indicator [13].

\section{Discussion}

Considering social projects, we should note that, unlike commercial projects, the consequences of implementation of social projects can be not always considered by the means of economic effect.

In many countries including Russia, expensive indicators prevail in statistics of healthcare and education. The statistics of healthcare operates with such data as the number of doctors, service personnel, hospitals, policlinics, hospital beds, charges, etc. But growth of these indicators is not followed by the corresponding improvement of health of the population. The statistics of education uses such indicators as the number of pupils, teachers and teachers, the number of students of average and higher educational institutions, release from educational institutions, costs of their contents. But all these indicators are only indirectly connected with the quality of education.

In this regard J. Stiglitz's commission in 2009 suggested to use the indicators of development of the social sphere which are not used today in statistics: these indicators include welfare or life expectancy and the influence, for example, of educational level on change of the aforesaid indicators [14].

In fact, the profit growth from rendering medical services or the increase in beds in hospitals do not always mean any corresponding decrease or growth of life expectancy of the population. Achievement of social or ecological results are often followed by negative economic effect. Therefore, not the assessment of efficiency of the social project, but the assessment of effectiveness comes out on top [15].

As the results differ depending on specifics of the social project, it is offered to differentiate effectiveness indicators in several integrated social directions: housing-andcommunal services, education, health- care, culture, sport and physical culture, transport.

Innovations in health care are necessary in order to optimize the system of the organization of medical care according to modern needs of the population, to improve availability of medical services, material and technical resources of medical institutions. These measures promote the extension of active able-bodied life of the population. 
Table 1. System of indicators for the assessment of social efficiency from the SIIP implementation in the directions of the social sphere

\begin{tabular}{|c|c|}
\hline Indicators for projects in housing sector [11] & Indicators for projects in education [12] \\
\hline $\begin{array}{l}\text { 1. Decrease in the expense of resources by } \\
\text { introduction of resource-saving technologies. } \\
\text { 2. Decrease in number of complaints from the } \\
\text { population because of quality and timeliness of } \\
\text { rendering of housing-and-communal services } \\
\text { due to introduction and development of new } \\
\text { equipment. } \\
\text { 3. Improvement of quality of drinking water } \\
\text { supply due to application of new methods of } \\
\text { water purification. } \\
\text { 4. Decrease in volume of garbage in house } \\
\text { adjoining territories due to implementation of } \\
\text { programmes of processing and recycling. } \\
\text { 5. Decrease in number of accidents in the } \\
\text { systems of engineering support due to the use } \\
\text { of new technologies. } \\
\text { 6. Decrease in the actual cost of rendering of } \\
\text { housing-and-communal services per } 1 \text { m }{ }^{2} \text { of } \\
\text { total area of housing in a month due to } \\
\text { introduction of resource-saving technologies. } \\
\text { 7. Increase in total area of housing stock, } \\
\text { including the increase due to application of new } \\
\text { design decisions and structures. } \\
\text { 8. Increase in living space on average per one } \\
\text { person, including due to application of new } \\
\text { design decisions and building structures. } \\
\text { 9. Increase in collecting of payments of the } \\
\text { population for housing-and-communal services. } \\
\text { 10. Decrease in level of the citizens' own } \\
\text { expenses on payment of housing and communal } \\
\text { services in the total revenues of families. }\end{array}$ & $\begin{array}{l}\text { 1. Increase in the share of the employed } \\
\text { population with special general education } \\
\text { owing to introduction of new ways of the } \\
\text { organization of occupations (distance learning, } \\
\text { IT technologies). } \\
\text { 2. Increase in the a share of the employed } \\
\text { population with higher professional education } \\
\text { owing to introduction of new ways of the } \\
\text { organization of occupations. } \\
\text { 3. Increase in level of literacy of the population } \\
\text { at the age of } 15 \text { and older. } \\
\text { 4. Increase in life expectancy (including the } \\
\text { assessment of impact of education level on } \\
\text { health). } \\
5 \text {. Increase in civil and public activity of the } \\
\text { population and also development of cultural life } \\
\text { of the population owing to the increase in } \\
\text { education level. } \\
\text { 6. Reduction of unemployment rate. } \\
\text { 7. Increase in the share of the busy population } \\
\text { at the age of } 25-55 \text {, who has undergone } \\
\text { professional development and retraining with } \\
\text { the use of innovative personnel retraining } \\
\text { programmes. } \\
8 \text {. Increase in providing of children aged from } 1 \\
\text { up to } 6 \text { with preschool institutions. } \\
\text { 9. Increase in coverage of children at the age of } \\
5-18 \text { with the programmes of additional } \\
\text { education owing to creation of various options } \\
\text { of full-day school, the psychological-and- } \\
\text { pedagogical centers and divisions of schools } \\
\text { and preschool institutions, creation of child } \\
\text { parental associations around schools or } \\
\text { preschool institutions, etc. } \\
10 \text {. Growth of social mobility and activity of } \\
\text { the youth. }\end{array}$ \\
\hline
\end{tabular}

Introduction of innovations in education leads to the 4 increase in availability and efficiency of education, growth of social mobility and activity of the population, its inclusiveness in various educational environments. Innovations in education allow to reduce illiteracy of residents of our country, to contribute to the harmonious development of the personality. It, finally, promotes the growth of welfare of citizens in Russia $[16,17]$.

Social innovations in transport influence the improvement of transport service for the population, growth of volumes and increase in efficiency of cargo transportation. Innovations to the transport sector provide the increase in the social standard of living of the population, stir up economic activity, promote development of new territories and resources. All this leads to the increase in rates of national income gain of the country.

The innovations in culture creating new forms and contents of cultural process lead to preservation and development of non-material cultural heritage of the people of Russia, 
contribute to the harmonious development of the personality and increase quality of life of the population.

Innovative changes in the sphere of physical culture and sport are directed to preservation and development of physical health of the population of Russia, to strengthening of health of the population and also to development of an educational system and the organization of leisure of various groups of the population as the physical culture and sport can be considered as a component of moral, esthetical and intellectual development of the population.

Innovative transformations in housing sector are capable to provide to the population the worthy conditions of accommodation meeting the modern quality standards of life, and introduction of innovations in the form of the use of resource-saving technologies has the exclusive importance for increase in efficiency, quality, reliability of the provided housing and communal services, decrease in irrational expenses $[18,19,20]$.

\section{Conclusion}

The innovative component during implementation of social projects can become one of fundamental factors of successful development of the social sphere. Social-and-economic development of Russia is now defined by social innovations, which can serve as the main instrument of improvement of quality of life of the population.

However it is not still possible to break some significant negative tendencies in the development of innovative system in our country, particularly in the development of social innovations. As the analysis of implementation of SIIP on the example of the Moscow region proves, among the reasons which are slowing down development of social innovations and social innovative projects it is possible to call the following: unwillingness to finance introduction of innovations private business, insufficiently efficient use of the public funds, allocated for research and development, insufficiently developed innovative policy of the region, lack of the serious methodological base, allowing to reflect objectively and most fully efficiency of the innovative projects realized in the social sphere and to choose projects among alternative.

The innovative component during implementation of social projects can become one of fundamental factors of successful development of the social sphere. Social-and-economic development of Russia is now defined by social innovations, which can serve as the main instrument of improvement of quality of life of the population.

However it is not still possible to break some significant negative tendencies in the development of innovative system in our country, particularly in the development of social innovations. As the analysis of implementation of SIIP on the example of the Moscow region proves, among the reasons which are slowing down development of social innovations and social innovative projects it is possible to call the following: unwillingness to finance introduction of innovations private business, insufficiently efficient use of the public funds, allocated for research and development, insufficiently developed innovative policy of the region, lack of the serious methodological base, allowing to reflect objectively and most fully efficiency of the innovative projects realized in the social sphere and to choose projects among alternative. For the purpose of a solution of the problem of lack of the mechanism by determination of the SIIP efficiency for their further selection to implementation, the author's technique including assessment of significance value and effectiveness of the social innovative- and-investment project, assessment of the budgetary effect of implementation of the project, social effect depending on its direction (healthcare, education, transport, housing-and-communal services, culture, physical culture and sport) and also the population assessment which quality of life improves as a result of realization of SIIP and determination of quantity of the created additional jobs, assessment of interests 
of future generations and compliance of implementation of the project to the principles of sustainable development is made.

\section{References}

1. N. Kondratyev, Big cycles of conjuncture and theory of anticipation (Moscow, Economy, 2002)

2. T. Parsons, On the structure of social action (Moscow, Academic project, 2002)

3. B. Santo Innovation's as the means of economic development (Moscow, Progress, 2008)

4. P. Druker, Business and innovations (Moscow, 2007)

5. J. Schumpeter, Theory of economic development (Moscow, Directmedia Publishing, 2008)

6. I. Polyakova, E. Vasilyeva, IOP (Earth and Environmental Science), 90012136 (2017)

7. E. Vasilyeva, IOP (Earth and Environmental Science), 90012216 (2017)

8. A. Mottaeva, IOP Conference Series: Earth and Environmental Science, 90, 012124 (2017)

9. A. Mottaeva, MATEC Web of Conferences, 73, 07020 (2016)

10. V. Glazkova, MATEC Web of Conferences, 106, 08095 (2017)

11. E. Vasilyeva, Economy and entrepreneurship, 6 (83), 607-610 (2017)

12. E. Vasilyeva, A. Zlentenkov, O. Suzneva, E. Sapozhnikova, IOP (Earth and Environmental Science), 90, 12122 (2017)

13. A. Bahauovna, A. Bahauovna, International Journal of Applied Engineering Research, 11 (9), 6808-6816 (2016)

14. Y. Prokhorova, I. Karakozova, Economy and Entrepreneurship, 6-3 (59-3), 608-613 (2015)

15. I. Polyakova, E. Chibisova, Economy and entrepreneurship, 4-1 (69-1), 816-819 (2016)

16. A. Mottaeva, J. Ćetković, Advances in Intelligent Systems and Computing, 692 11511159 (2018)

17. V. Glazkova, MATEC Web of Conferences, 106, 08096 (2017)

18. Akimova, E.M., Stein, E.M. , Prokhorova, Y.S. Journal of Advanced Research in Law and Economics, 6-3, 472-487 (2015)

19. A. Bahauovna, A. Bahauovna, International Journal of Applied Engineering Research, 10 (23), 43446-43449 (2015)

20. Akimova E.M., Knyazev D.V International Journal of Applied Engineering Research, 10 (18), 39387-39394 (2015) 